Supplementary Information

\title{
Detailed inventory of the evaporative emissions from parked gasoline vehicles and an evaluation of their atmospheric impact in Japan
}

\author{
Hiroo Hataa,d, ${ }^{*}$ Kazuya Inoue ${ }^{b}$, Kazuo Kokuryoc, and Kenichi Tonokurad, * \\ a Tokyo Metropolitan Research Institute for Environmental Protection 1-7-5, Sinsuna, \\ Koto-ku, Tokyo 136-0075, Japan \\ ${ }^{b}$ Research Institute of Science for Safety and Sustainability, The National Institute of \\ Advanced Industrial Science and Technology, 1-1-1 Umezono, Tsukuba, Ibaraki \\ 305-8560, Japan \\ c Modern Planning Inc. 5-49-10 Chuo, Nakano-ku, Tokyo 164-0011, Japan \\ a Department of Environment Systems, Graduate School of Frontier Sciences, The \\ University of Tokyo, 5-1-5 Kashiwanoha, Kashiwa, Chiba 277-8563, Japan
}

${ }^{*}$ Corresponding author. E-mail: hata-h@tokyokankyo.jp; Tel: +81-3-3699-1369

E-mail: tonokura@k.u-tokyo.ac.jp; Tel: +81-4-7136-4706 


\section{Contents (36 pages, 18 Figures, and 8 Tables)}

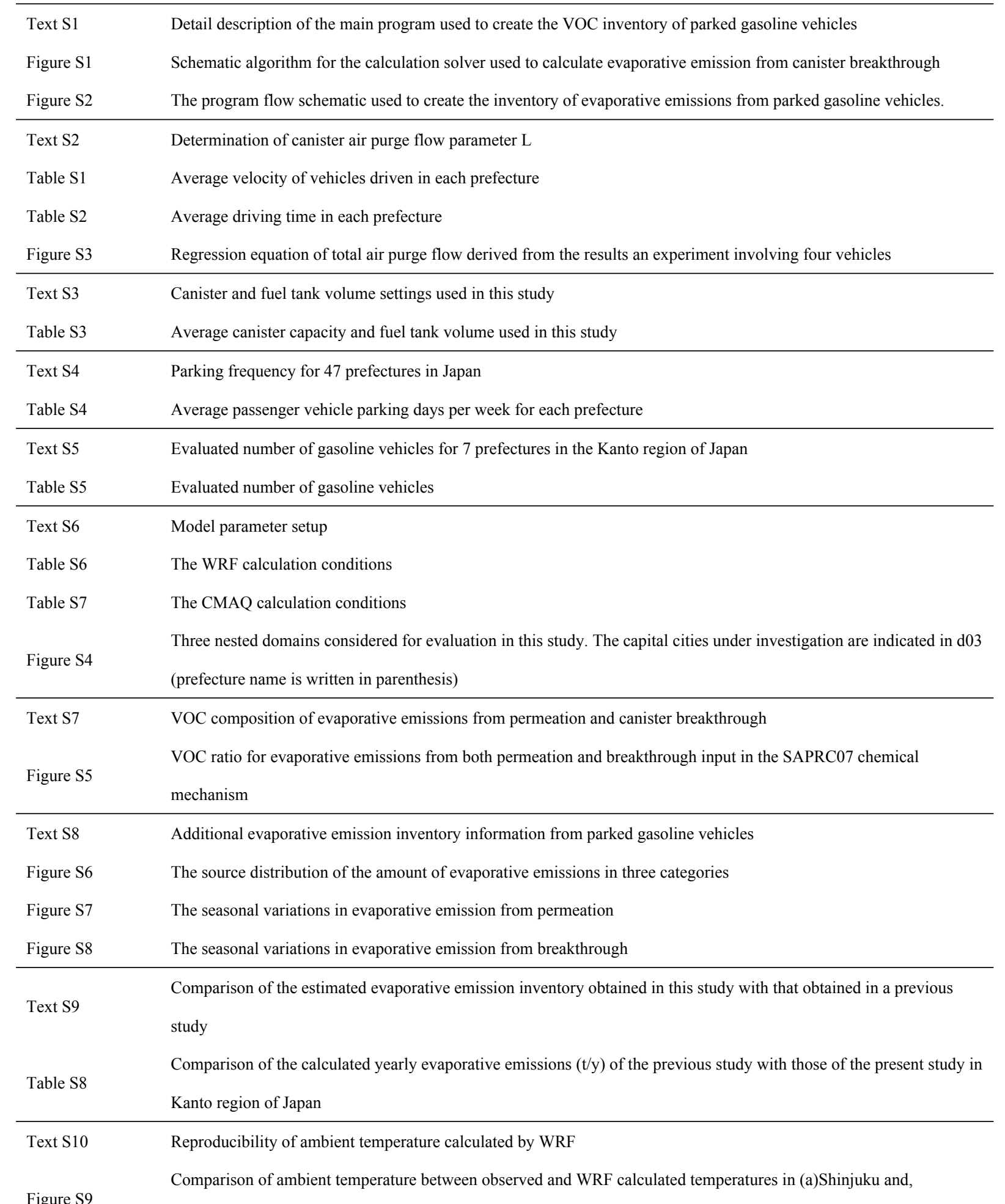

(b)Yokohama. Compared term is from July 10 to August 15, 2015.

Figure S10

Comparison of ambient temperature between observed and WRF calculated temperatures in (a)Chiba and, (b)Saitama.

Compared term is from July 10 to August 15, 2015. 
Figure S11

Comparison of ambient temperature between observed and WRF calculated temperatures in (a)Utsunomiya and,

(b)Maebashi. Compared term is from July 10 to August 15, 2015.

Figure S12

Comparison of ambient temperature between observed and WRF calculated temperatures in Mito. Compared term is

from July 10 to August 15, 2015 .

Text S11 Model validation for tropospheric ozone and $\mathrm{PM}_{2.5}$ concentration in seven prefectures in Japan

Figure S13 Comparison between the CMAQ calculation results and observational data for tropospheric ozone concentration

Figure S14 Comparison between the CMAQ calculation results and observational data for $\mathrm{PM}_{2.5}$ concentration

Text S12 Ozone concentration and wind-vector map

Figure S15 Hourly observed ozone concentration and wind-vector analysis for July 27, 2015

Figure S16 Hourly observed ozone concentration and wind-vector analysis for July 28, 2015

Section S13 Time profile of calculated evaporative emissions

Figure S17

Time profile of summertime evaporative emissions in seven prefectural cities for (a) permeation, (b) breakthrough, and

(c) total evaporation of permeation and breakthrough

Text S14 Effect of hot-soak loss (HSL) on ozone and SOA formation

Figure S18 The results of the sensitivity analysis of the reduction in evaporative emissions

1 


\section{Text S1 Detailed description of the main program used to create the}

3 VOC inventory of parked gasoline vehicles

4 The amount of VOCs emitted from parked gasoline vehicles was calculated using the calculation scheme proposed in our previous study ${ }^{1}$. The evaporative emission from permeation through fuel system-related parts $(\mathrm{g} / \mathrm{h}), \Delta w_{\text {perm }}$, was calculated using the following equation:

$$
\Delta w_{\text {perm }}=0.01 \exp \{0.0385(T-72)\}
$$

11 where $T$ is the temperature of empty fuel tank volume (deg F). It has been demonstrated that equation (S1) is suitable for the analysis of experimental results collected from two passenger vehicles in the Japanese market; however, information on its suitability for other vehicles types, including heavy-duty vehicles and motorcycles, is still lacking. Nonetheless, no other equations have been reported in previous studies. Thus, it was assumed to be suitable for the determination of the amount of permeation emissions from all vehicles types. The calculation algorithm describing evaporative emission from canister breakthrough is shown in Figure S1.

19 This is based on the material balance inside the carbon canister. While parked, 
gasoline evaporation from the fuel tank occurred due to diurnal air temperature changes. The amount of evaporation from the fuel tank $(\mathrm{g} / \mathrm{h}), \Delta w_{\text {tank}}$, was calculated using the following equation:

$$
\Delta w_{\text {tank }}=\left\{\begin{array}{c}
\frac{M V_{\text {tank }} P \exp }{\Delta H}\left[\exp \left\{\frac{\Delta H}{R}\left(\frac{1}{T_{\mathrm{r}}}-\frac{1}{T_{t+1}}\right)\right\}-\exp \left\{\frac{\Delta H}{R}\left(\frac{1}{T_{\mathrm{r}}}-\frac{1}{T_{t}}\right)\right\}\right]\left(T_{t+1}>T_{t}\right) \\
0 \quad\left(T_{t+1} \leq T_{t}\right)
\end{array}\right.
$$

Where, $M$ is the molecular weight $(\mathrm{g} / \mathrm{mol}), V_{\text {tank }}$ is the empty fuel tank volume $(\mathrm{L}), P_{\exp }$ is the Reid vapor pressure related parameter $(\mathrm{kPa}), \Delta H$ is the gasoline evaporation enthalpy $(\mathrm{J} / \mathrm{mol}), R$ is the gas constant $(8.312 \mathrm{~J} /(\mathrm{K} \mathrm{mol})), T_{\mathrm{r}}$ is the temperature at the definition of the Reid vapor pressure $(311 \mathrm{~K})$, and $T_{t}$ is the environmental temperature at time $t(\mathrm{~K})$. When the amount of adsorbed VOCs $(C)$ reaches the maximum adsorption capacity of the canister $\left(C_{\max }\right)$, canister breakthrough occurs and the evaporative emissions from the fuel tank are directly emitted into the atmosphere. Furthermore, considering the long duration of fuel consumption, it was assumed that all the canisters would have deteriorated, and their adsorption capacity would have reduced by half relative to the maximum adsorption capacity of a brand-new canister. Finally, when the vehicle is run after being parked, VOCs 
trapped within the canister are purged by the air which is used in engine combustion.

The amount of purged VOCs ( $\left.\Delta w_{\text {desorp }}\right)$ was calculated using the following equation.

$$
\frac{\Delta w_{\text {desorp }}}{C_{\max }}=\left(\frac{C}{C_{\max }}\right)^{1.55}\left(1-e^{-0.00586 L}\right)
$$

Where $L$ is total air purge flow inside canister $(L)$. In our previous study ${ }^{1}$, the transition state from non-breakthrough and breakthrough was defined, and among this state, breakthrough emission is not equal to the evaporative emission from the fuel tank given that several amounts of the evaporation are still trapped inside the canister (the ratio of trapped evaporation was defined as $\theta$ ). Regardless of this previous definition, the transition state was not considered as an approach to simplify the calculation model in this study. Additionally, the sensitivity analysis of the effect of the transition state was conducted; however, it affected only a small percentage of the evaporative emissions from the first breakthrough time. Thus, it was concluded that the elimination of the transition state is not critical. Furthermore, evaporative emissions from canisters were assumed to occur any time before breakthrough caused by the trapping loss. The amount of trapping loss of evaporative emissions has not been measured, and this phenomenon was not considered in the calculation 
model in Figure S1. This means that the amount of evaporative emissions may have been underestimated. The introduction of trapping loss should therefore be considered in future research. Once statistical information, such as the canister capacity for each vehicle type, parking frequency for each city, and environmental temperature are obtained, the amount of evaporative emissions for an arbitrary time and place can be calculated. Further details are provided in our previous paper ${ }^{1}$. Additionally, in this study, once the calculation program software, which is schematically presented in Figure S2, was developed, the evaporative emission inventory was generated based on the algorithm described in Figure S1. All the calculation programs were developed using Fortran 95, and the authors are ready to make it completely available to the readers of this article. If the readers want to check the detailed source code, they can contact the corresponding authors.

$$
\begin{aligned}
& \text { Desorption }\left(\Delta \mathbf{w}_{\text {desorp }}\right) \\
& \frac{\Delta w_{\text {desorp }}}{C_{\max }}=\left(\frac{C}{C_{\max }}\right)^{1.55}\left(1-e^{-0.00586 L}\right)
\end{aligned}
$$

$$
\begin{aligned}
\text { Fuel tank }\left(\Delta \mathbf{w}_{\text {tank }}\right) & \text { Breakthrough }\left(\Delta \mathbf{w}_{\mathbf{b}}\right) \\
\Delta \boldsymbol{w}_{\text {tank }}=\frac{M V_{m} P_{\exp }}{\Delta H_{m}} & {\left[\exp \left\{\frac{\Delta H_{m}}{R}\left(\frac{1}{T_{r}}-\frac{1}{T_{2}}\right)\right\}\right.} \\
& \left.-\exp \left\{\frac{\Delta H_{m}}{R}\left(\frac{1}{T_{r}}-\frac{1}{T_{1}}\right)\right\}\right]
\end{aligned}
$$

\section{Canister}




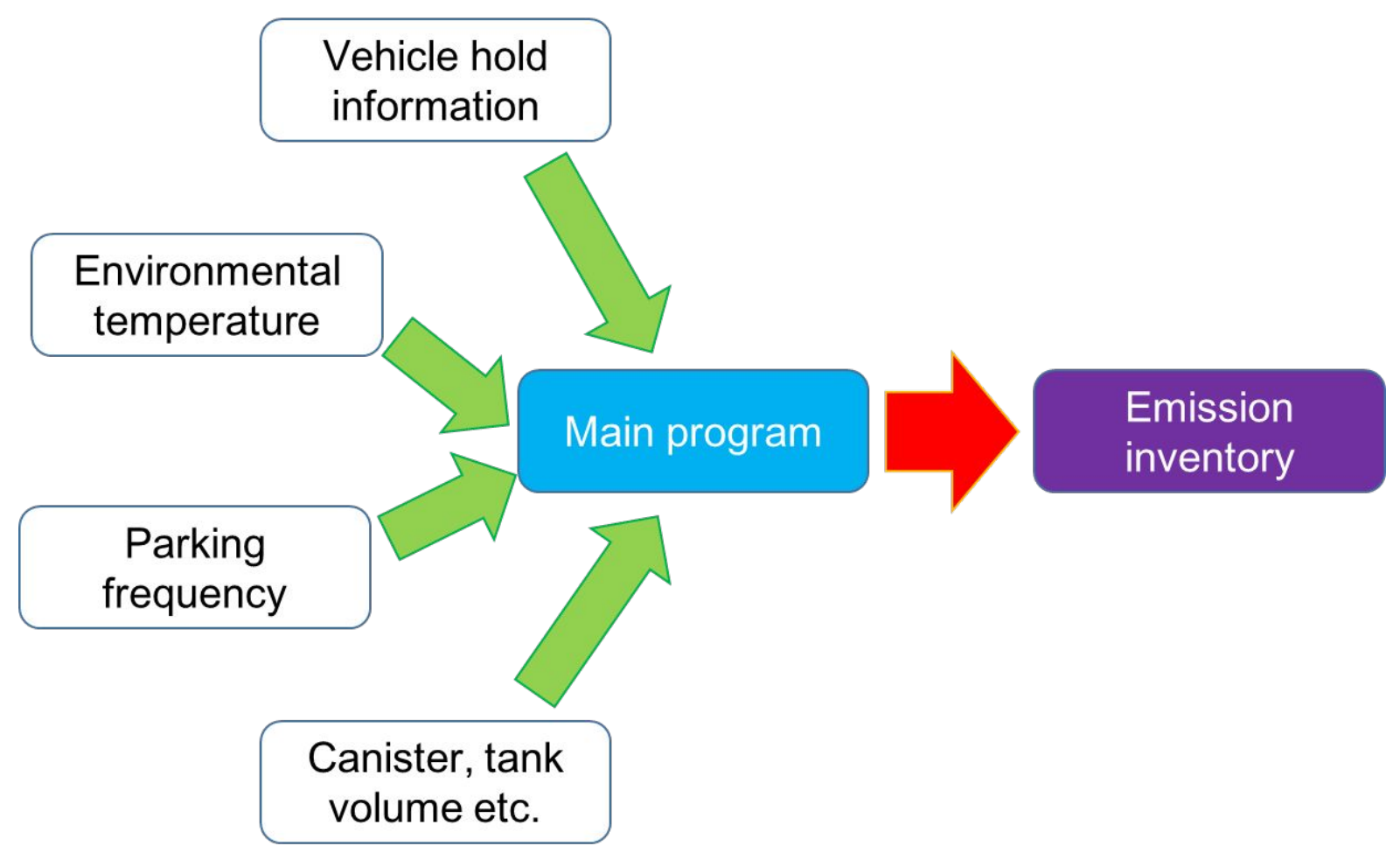

Figure S2: The program flow schematic used to create the inventory of evaporative emissions from parked gasoline vehicles.

\section{Text S1 Reference}

1. Hata, Hiroo et al. Modeling evaporative emissions from parked gasoline cars based on carbon canister experiments. Science of the Total Environment. 2019, 
To evaluate average air purge flow parameter $L$, we used the following relationships between the air purge flow per $\mathrm{km} L_{0}(\mathrm{~L} / \mathrm{km})$, the average driving distance $\Delta x$, and the average velocity of each vehicle $v_{\mathrm{a}}$ :

84

$$
L_{0}=0.0039 v_{\mathrm{a}}^{2}-0.3302 v_{\mathrm{a}}+8.9513
$$

$$
L=L_{0} \Delta x
$$

Equation S4 was derived from chassis dynamometer experiments performed with four gasoline passenger vehicles. The measured driving modes were the Tokyo driving patterns No.1-10 and No.12, and further details regarding the tested modes are described in our previous study ${ }^{2}$. The average velocity $v_{a}$ was cited from a statistical survey conducted in the 47 prefectures in Japan by the Ministry of Land, Infrastructure, Transport, and Tourism ${ }^{3}$. The value of $v_{a}$ in each prefecture used in this study is listed in Table S1. The average distance travelled per drive in each prefecture was calculated based on the average velocity listed in Table S1 and the average driving time per drive: $v_{\mathrm{a}} \times t_{\mathrm{a}} \times 60$, where $t_{\mathrm{a}}$ is the average driving time (min). 
The average driving time was cited from the results of a questionnaire conducted by

The University of Tokyo. Further details are provided in Table S2. The average

distance travelled per drive was calculated using average speed and driving time per day, and the total driving time comprised a number of shorter driving events. The purge effect evaluated by the parameters in Tables S1 and S2 could, therefore, include errors, especially for short-distance driving activities in real-world situations.

\section{This kind of error can be solved when detailed driving activity is input into the} calculation model (equation (S3)).

The average driving speed in Beijing, China was reported in the previous study ${ }^{4}$ and the value is $23.57 \mathrm{~km} / \mathrm{h}$, which is similar to the value of Tokyo. Both of the cities are metropolitan area, and thus, the real-world road situation is almost the same between each city.

Table S1: Average velocity of vehicles driven in each prefecture.

\begin{tabular}{lc:lc:lc}
\hline Prefecture & Velocity $(\mathrm{km} / \mathrm{h})$ & Prefecture & Velocity $(\mathrm{km} / \mathrm{h})$ & Prefecture & Velocity $(\mathrm{km} / \mathrm{h})$ \\
\hline Hokkaido & 43.3 & Ishikawa & 38.9 & Okayama & 36.3 \\
Aomori & 38.4 & Fukui & 38.3 & Hiroshima & 36.8 \\
Iwate & 43.3 & Yamanashi & 37.8 & Yamaguchi & 42.1 \\
Miyagi & 37.7 & Nagano & 37.2 & Tokushima & 32.8 \\
Akita & 42.8 & Gifu & 37.4 & Kagawa & 35.7 \\
Yamagata & 37.7 & Shizuoka & 36.6 & Ehime & 37.2 \\
Fukushima & 40.4 & Aichi & 30.7 & Kochi & 36.1 \\
Ibaraki & 37.0 & Mie & 37.3 & Fukuoka & 32.2
\end{tabular}




\begin{tabular}{ll|ll|ll} 
Tochigi & 38.1 & Shiga & 39.2 & Saga & 37.6 \\
Gunma & 34.2 & Kyoto & 31.8 & Nagasaki & 35.0 \\
Saitama & 30.4 & Osaka & 29.0 & Kumamoto & 35.8 \\
Chiba & 34.2 & Hyogo & 37.6 & Oita & 37.5 \\
Tokyo & 24.6 & Nara & 31.5 & Miyazaki & 38.6 \\
Kanagawa & 30.3 & Wakayama & 33.9 & Kagoshima & 38.0 \\
Niigata & 40.3 & Tottori & 37.7 & Okinawa & 29.1 \\
Toyama & 34.6 & Shimane & 40.3 & & \\
\hline
\end{tabular}

112

Table S2: Average driving time in each prefecture.

\begin{tabular}{lc:|lc:ll}
\hline Prefecture & Time (min) & Prefecture & Time $(\mathrm{min})$ & Prefecture & Time (min) \\
\hline Hokkaido & 50.6 & Ishikawa & 54.9 & Okayama & 59.9 \\
Aomori & 53.2 & Fukui & 57.9 & Hiroshima & 47.6 \\
Iwate & 52.0 & Yamanashi & 53.9 & Yamaguchi & 50.7 \\
Miyagi & 58.3 & Nagano & 50.4 & Tokushima & 55.2 \\
Akita & 51.6 & Gifu & 52.4 & Kagawa & 51.1 \\
Yamagata & 46.8 & Shizuoka & 51.2 & Ehime & 50.3 \\
Fukushima & 52.9 & Aichi & 53.9 & Kochi & 58.0 \\
Ibaraki & 52.7 & Mie & 49.4 & Fukuoka & 53.3 \\
Tochigi & 52.1 & Shiga & 50.6 & Saga & 57.8 \\
Gunma & 53.7 & Kyoto & 49.5 & Nagasaki & 59.1 \\
Saitama & 46.7 & Osaka & 52.7 & Kumamoto & 57.8 \\
Chiba & 53.0 & Hyogo & 53.4 & Oita & 52.8 \\
Tokyo & 50.0 & Nara & 54.3 & Miyazaki & 51.5 \\
Kanagawa & 45.7 & Wakayama & 56.0 & Kagoshima & 55.0 \\
Niigata & 48.6 & Tottori & 51.5 & Okinawa & 59.2 \\
Toyama & 53.4 & Shimane & 52.1 & & \\
\hline
\end{tabular}




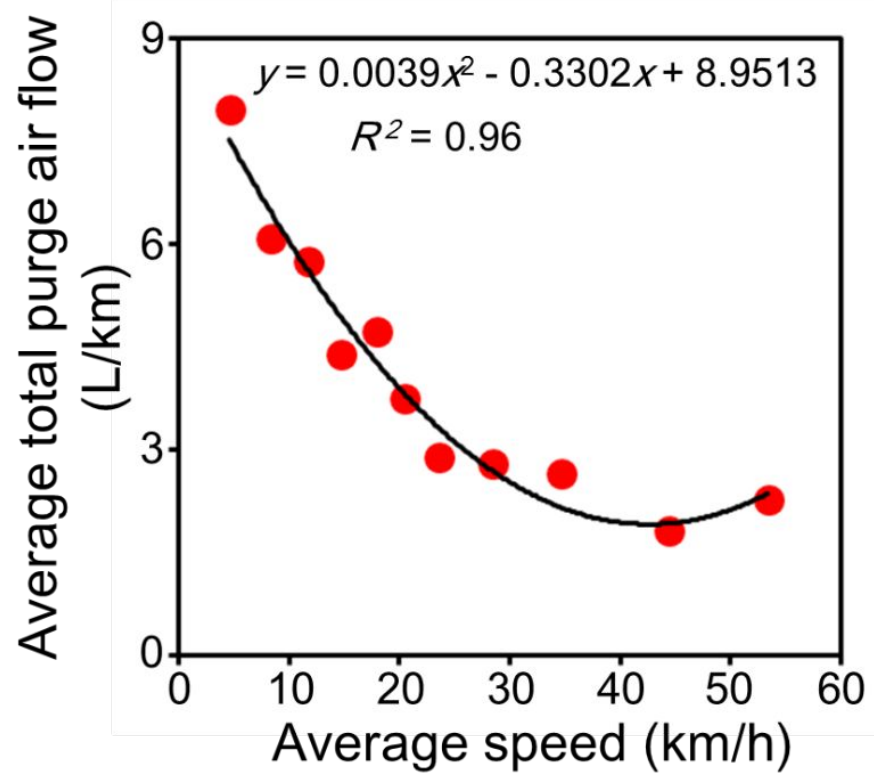

116

117 Figure S3: Regression equation of total air purge flow derived from the results of an 118 experiment involving four vehicles.

2. Hata and Tonokura. Impact of next-generation vehicles on tropospheric ozone estimated by chemical transport model in the Kanto region of Japan. Scientific Reports. 2019, 9, 3573. https://www.nature.com/articles/s41598-019-40012-y. 
128 The average canister capacity (g), which corresponds to $C_{\max }$ in equation (S3), along 129 with the fuel tank volume (L) for each vehicle type used in this study was cited from a 130 previous statistical study conducted by the Japan Auto Oil Program (JATOP) ${ }^{3}$, and 131 the value are listed in Table S3.

132 Table S3: Average canister capacity and fuel tank volume used in this study.

\begin{tabular}{lcc}
\hline Type & Canister capacity $(\mathrm{g})$ & Fuel tank volume (L) \\
\hline Mini-sized passenger vehicle & 26 & 30.8 \\
Passenger vehicle & 40 & 70.4 \\
Bus (Vehicle weight $<3.5 \mathrm{t}$ ) & 32 & 65.4 \\
Bus (Vehicle weight $>3.5 \mathrm{t})$ & 32 & 70 \\
Mini-sized truck & 30 & 40.1 \\
Light-duty vehicle & 37 & 65.4 \\
Heavy-duty vehicle & 37 & 70 \\
Vehicle for specific use & 37.2 & 67.7 \\
Motercycle & 0 & 18.1 \\
\hline
\end{tabular}

134 Text S3 Reference

4. Technological report of JATOP. Japan Auto Oil Program. 2012. 
139 In this study, questionnaires regarding household vehicle use information were

140 administered in 47 prefectures in Japan in 2017. In each prefecture, 400

141 questionnaires were administered, making a total number of 18,800 , and the validity

142 of the number of questionnaires, $n$, was evaluated using equation (S5).

143

$144 n=\frac{N}{\frac{E^{2}}{1.96^{2}} \times \frac{N-1}{P(100-P)}+1}$

where $N, E, P$ represent the parent population, allowable error, and response rate

147 (\%), respectively. When the allowable error and response rate were set at $E=0.05$

and $P=50$, respectively, the actual number of questionnaires was determined as 370

149 for a parent population $>1000$. Thus, 400 questionnaires were administered in each prefecture, and the information collected included: prefecture of respondent, weekly

151 frequency of household vehicle usage, average daily driving distance, vehicle usage purpose, refueling frequency, etc. From the information regarding the prefecture of

153 the respondents and their weekly frequency of vehicle usage, the average weekly passenger vehicle parking days for each prefecture was evaluated, and the results are presented in Table S4. 
156 A previous study conducted in China ${ }^{4}$ also revealed parking and driving activities.

157 Average parking days in Beijing were estimated to be 2.3 days/week. The parking

158 frequency in the Beijing metropolitan area was lower than that in the Tokyo

159 metropolitan area (4.7 days/week). Most Tokyo residents who own cars tend to use

160 public transportation on weekdays. Cars are mainly used on weekends, resulting in

161 the differences in parking frequency between Beijing and Tokyo.

162

163 Table S4: Average passenger vehicle parking days per week for each prefecture.

\begin{tabular}{|c|c|c|c|c|c|}
\hline Prefecture & $\begin{array}{l}\text { Parking } \\
\text { days/week }\end{array}$ & Prefecture & $\begin{array}{l}\text { Parking } \\
\text { days/week }\end{array}$ & Prefecture & $\begin{array}{l}\text { Parking } \\
\text { days/week }\end{array}$ \\
\hline Hokkaido & 2.4 & Ishikawa & 1.4 & Okayama & 1.9 \\
\hline Aomori & 1.7 & Fukui & 1.4 & Hiroshima & 2.9 \\
\hline Iwate & 1.7 & Yamanashi & 1.7 & Yamaguchi & 1.8 \\
\hline Miyagi & 2.4 & Nagano & 1.7 & Tokushima & 2.0 \\
\hline Akita & 1.4 & Gifu & 1.9 & Kagawa & 2.1 \\
\hline Yamagata & 1.3 & Shizuoka & 1.8 & Ehime & 2.3 \\
\hline Fukushima & 1.6 & Aichi & 2.6 & Kochi & 2.1 \\
\hline Ibaraki & 2.0 & Mie & 1.8 & Fukuoka & 2.7 \\
\hline Tochigi & 1.9 & Shiga & 2.4 & Saga & 1.8 \\
\hline Gunma & 1.5 & Kyoto & 3.6 & Nagasaki & 2.1 \\
\hline Saitama & 3.7 & Osaka & 4.0 & Kumamoto & 2.0 \\
\hline Chiba & 3.7 & Hyogo & 3.3 & Oita & 1.9 \\
\hline Tokyo & 4.7 & Nara & 3.2 & Miyazaki & 1.6 \\
\hline Kanagawa & 4.1 & Wakayama & 2.2 & Kagoshima & 1.8 \\
\hline Niigata & 1.9 & Tottori & 1.6 & Okinawa & 1.9 \\
\hline Toyama & 1.2 & Shimane & 1.4 & & \\
\hline
\end{tabular}


4. Liu, H.; Man, H.; Cui, H.; Wang, Y.; Deng, F.; Wang, Y.; Yang, X.; Xial, Q.; Zhang,

Q.; Ding, Y.; He, K. An updated emission inventory of vehicular VOCs and IVOCs in

China. Atmospheric Chemistry and Physics. 2017, 17, 12709-12724.

169 https://doi.org/10.5194/acp-17-12709-2017.

170

171 Text S5 Evaluated number of gasoline vehicles for 7 prefectures in the

Table S5: Evaluated number of gasoline vehicles.

\begin{tabular}{lc}
\hline Prefecture & Number of gasoline vehicle \\
\hline Ibaraki & $2,347,898$ \\
Tochigi & $1,710,953$ \\
Gunma & $1,612,408$ \\
Saitama & $3,960,308$ \\
Chiba & $3,298,253$ \\
Tokyo & $3,811,679$ \\
Kanagawa & $3,559,071$ \\
\hline
\end{tabular}


Table S6: The WRF calculation conditions.

\begin{tabular}{ll}
\hline Model & WRF-ARW v3.7.1 \\
\hline Reanalysis & NCEP FNL (1 deg., $6 \mathrm{hr})$ \\
SST & RTG_SST_HR (1/12 deg., daily) \\
Domains & $220 \times 170, \sim 45 \mathrm{~km}(\mathrm{~d} 01), 154 \times 160, \sim 15 \mathrm{~km}(\mathrm{~d} 02), 64 \times 70, \sim 5 \mathrm{~km}$ \\
& $(\mathrm{~d} 03)$ \\
Number of vertical layers & 31 (for all domains) \\
Minimum vertical pressure (p_top) & $100 \mathrm{hPa}$ \\
Grid nudging & k_zfac_uv $=10$ \\
& guv, gt, gq $=0.0001$ (d01), 0.00005 (d02), 0.0 (d03) \\
Microphysics & WRF Single-Moment 5-class scheme \\
Longwave radiation & RRTM scheme \\
Shortwave radiation & Dudhia scheme \\
Planetary boundary layer & Mellor-Yamada Nakanishi and Niino Level 3 PBL scheme \\
Culoud physics & Kain-Fritsch scheme \\
\hline
\end{tabular}

Table S7: The CMAQ calculation conditions.

\begin{tabular}{ll}
\hline Model & CMAQv5.2 \\
\hline Boundary concentration $(\mathrm{d} 01)$ & MOZART-4 \\
Boundary concentration $(\mathrm{d} 02)$ & Nested from d01 \\
Boundary concentration (d03) & Nested from d02 \\
Initial concentration (d01) & CMAQ default (profile) \\
Initial concentration $(\mathrm{d} 02)$ & Nested from d01 \\
Initial concentration $(\mathrm{d} 03)$ & Nested from d02 \\
Domains & $207 \times 157(\mathrm{~d} 01), 141 \times 147(\mathrm{~d} 02), 51 \times 57(\mathrm{~d} 03)$ \\
Gas chemistry & saprc07tc \\
Aerosol chemistry & aero6 \\
Aqueous chemistry & cloud_acm_ae6 \\
Photolysis & phot_inline \\
Horizontal advection & yamo \\
Vertical advection & wrf \\
Horizontal diffusion & hdiff/multiscale
\end{tabular}




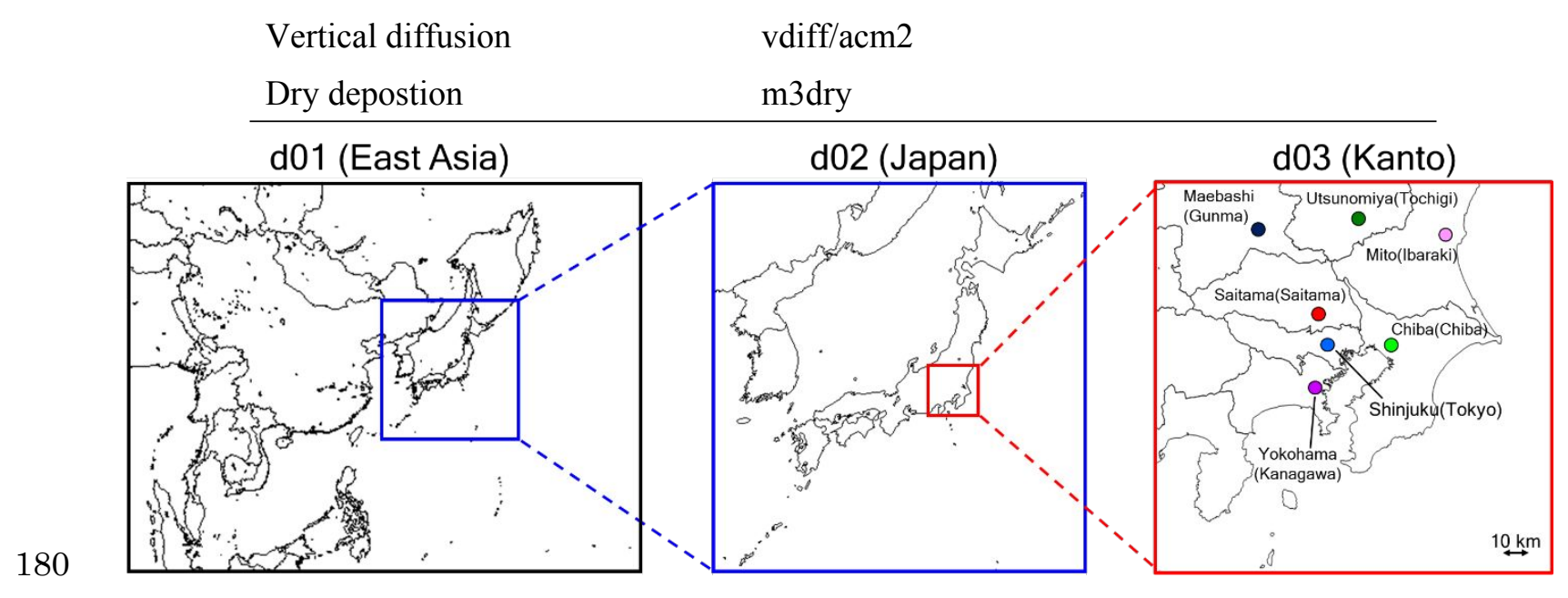

181 Figure S4: Three nested domains considered for evaluation in this study. The capital

182 cities under investigation are indicated in d03 (prefecture name is written in

183 parenthesis). 


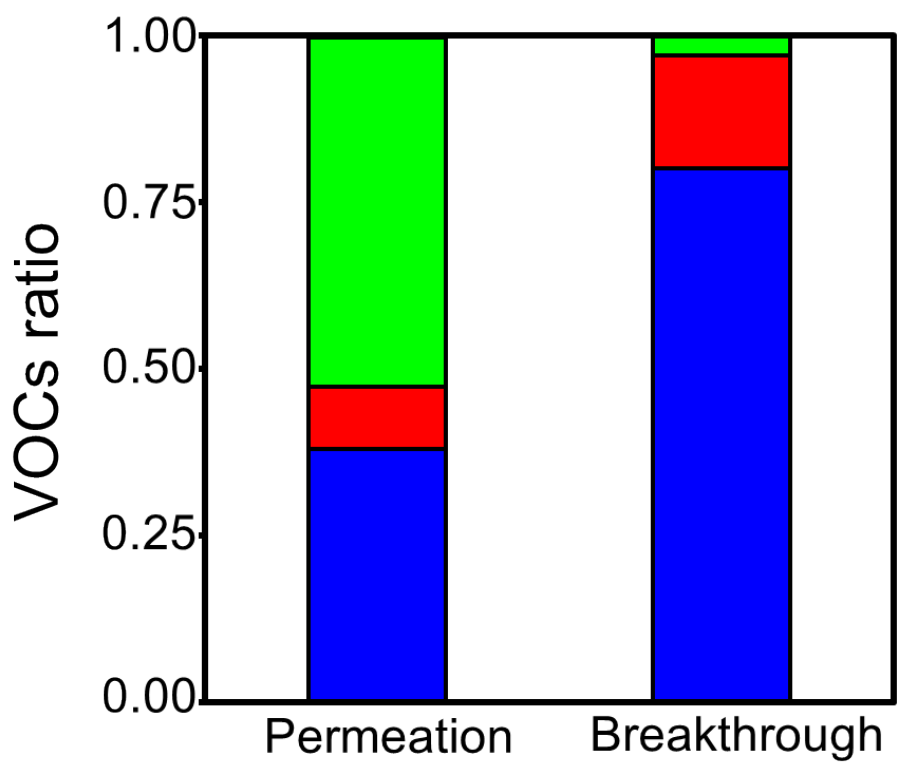

189 Figure S5: VOC ratio for evaporative emissions from both permeation and and Diene, : Aromatic).

193 The species compositions shown in Figure S5 were obtained from the previous study.

194 The DBL composition analysis results for the first few hours were considered as the 195 permeation composition. 

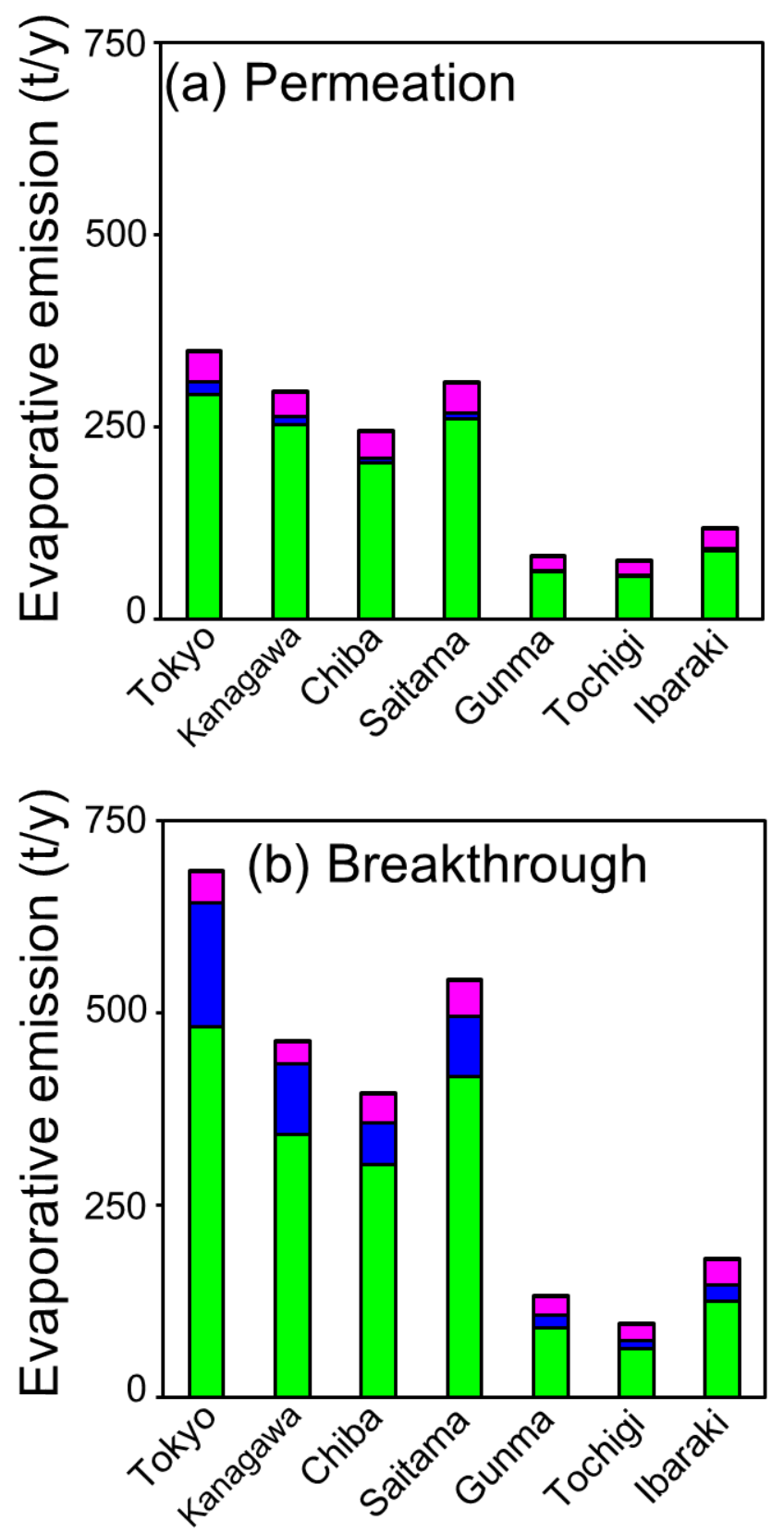

200 Figure S6: The source distribution of the amount of evaporative emissions in three

201 categories for (a)Permeation and (b)Breakthrough ( $\square$ : Passenger vehicles, 
202 Motorcycles, :Heavy-duty vehicles). 
$\mathrm{kg} /\left(\mathrm{km}^{2} \mathrm{month}\right)$
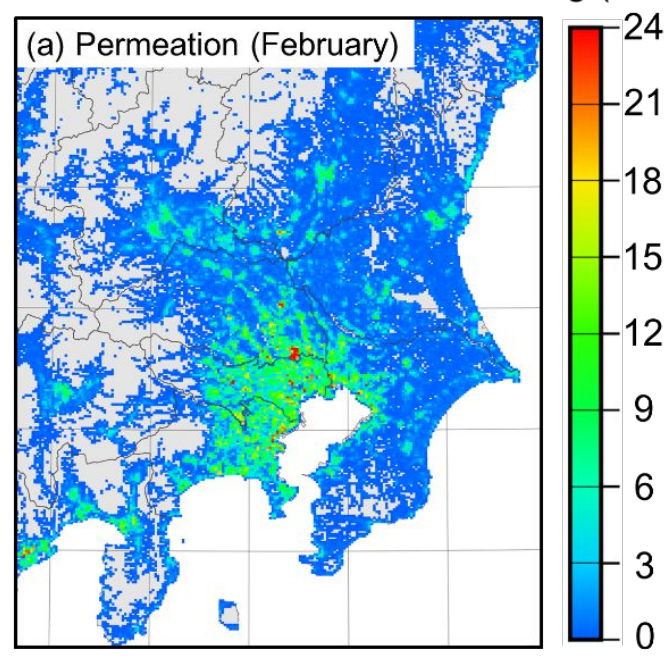

$\mathrm{kg} /\left(\mathrm{km}^{2}\right.$ month $)$
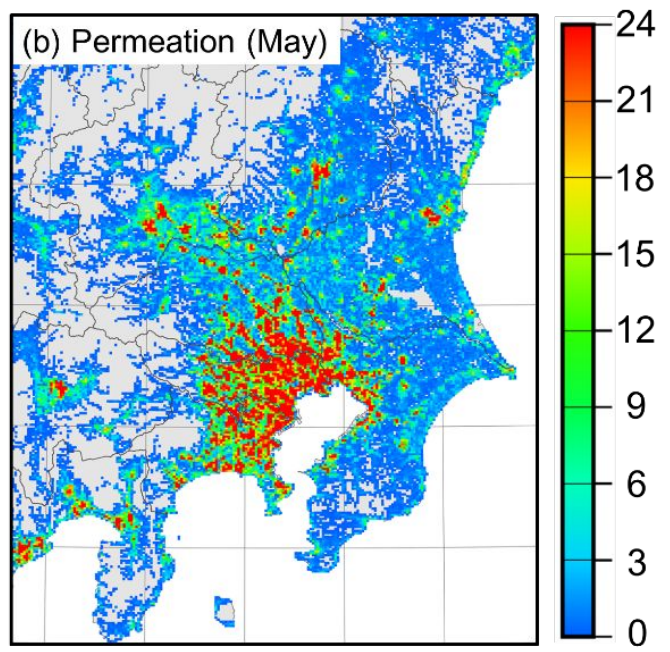

$\mathrm{kg} /\left(\mathrm{km}^{2}\right.$ month $)$

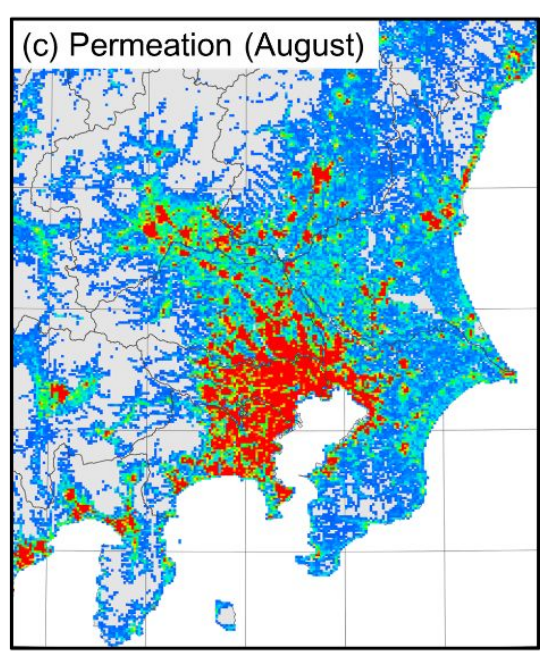

$\mathrm{kg} /\left(\mathrm{km}^{2}\right.$ month $)$
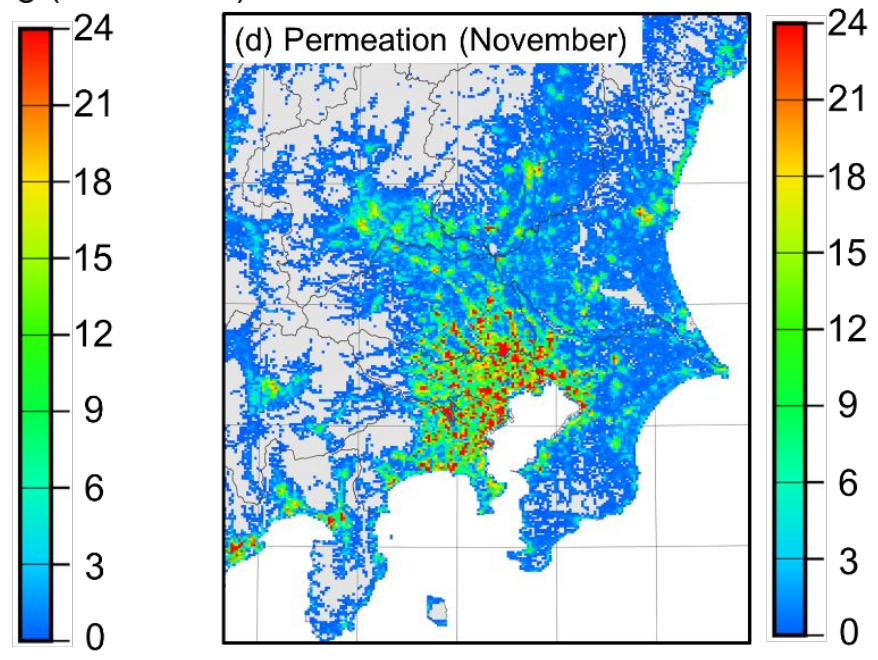

204

205

Figure S7: The seasonal variations in evaporative emission from permeation. 
$\mathrm{kg} /\left(\mathrm{km}^{2}\right.$ month $)$
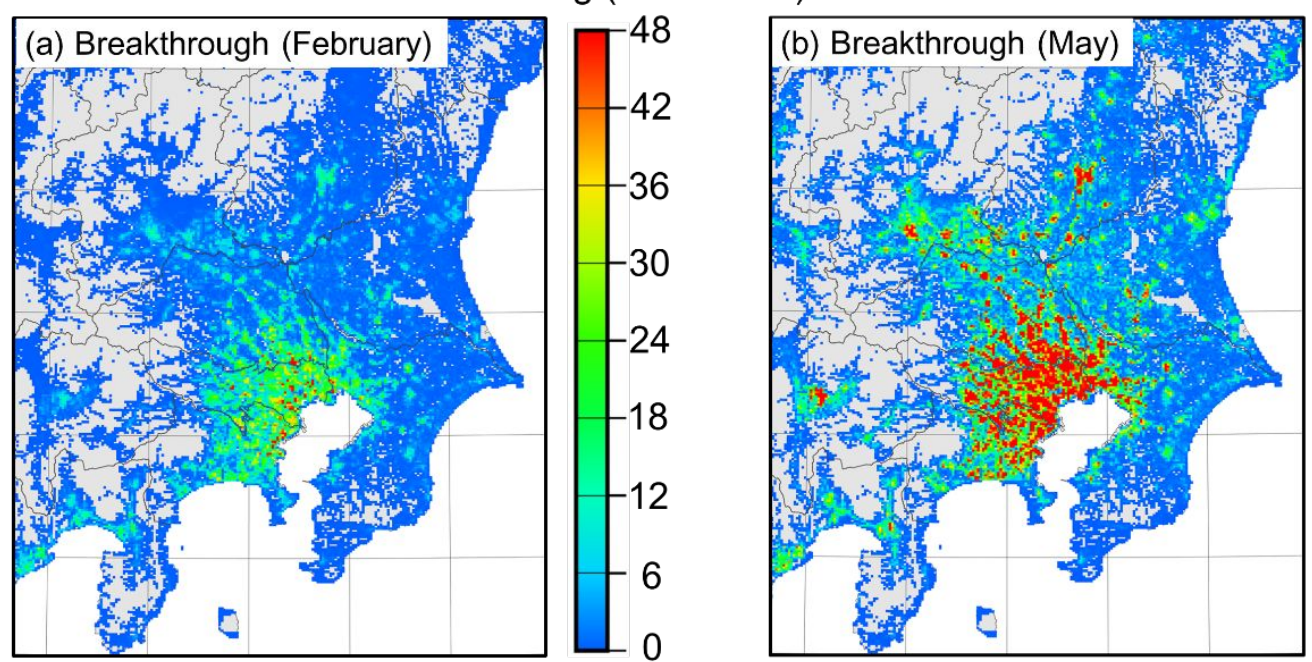

$\mathrm{kg} /\left(\mathrm{km}^{2} \mathrm{month}\right)$

\section{$\mathrm{kg} /\left(\mathrm{km}^{2}\right.$ month $)$}
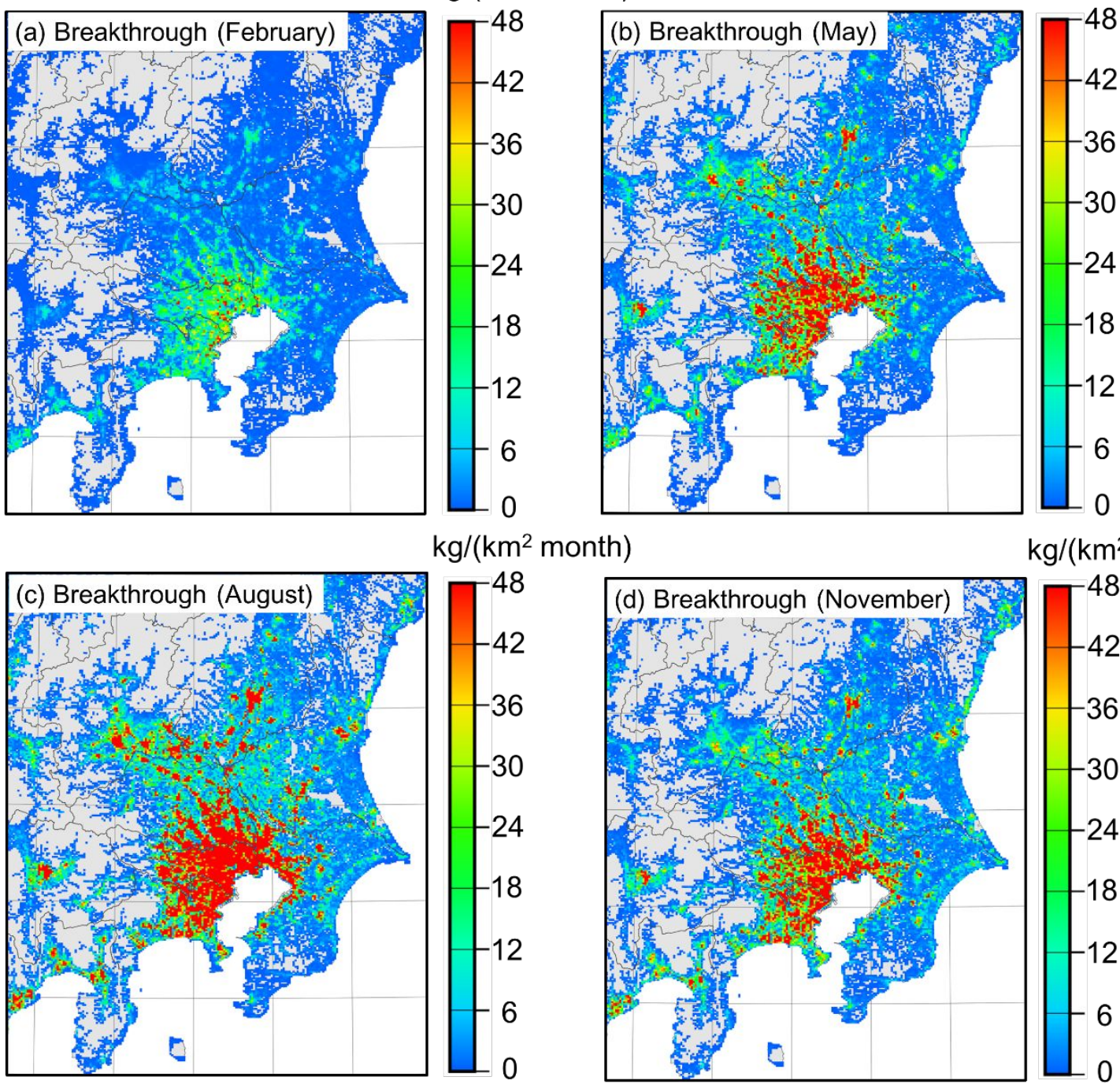

$\mathrm{kg} /\left(\mathrm{km}^{2} \mathrm{month}\right)$

207

Figure S8: The seasonal variations in evaporative emission from breakthrough. 
210 Text S9 Comparison of the estimated evaporative emission inventory

211 obtained in this study with that obtained in a previous study (JATOP)

212 The evaporative emission inventory from parked gasoline vehicles in Japan had been

213 previously evaluated by the Japan Auto-Oil Program (JATOP) ${ }^{5}$. The evaluation

214 methods employed in this study were based on this previous JATOP study. However,

215 for the following reasons, the methods were upgraded.

$216 \cdot$ In the JATOP study the amount of evaporation from fuel tanks was calculated

217 using Reddy's equation ${ }^{6}$. However, in this study equation (S2), which has been

218 proven to be more accurate was used.

219 - Our updated method considered the canister purge effect described by equation

220 (S3) as the initial canister condition. This effect was not considered in the JATOP

221 study.

222 - In the JATOP, only the permeation effect that occurred before canister

223 breakthrough was considered. Furthermore, the amount of permeation was

224 considered to be constant at $0.04 \mathrm{~g} / \mathrm{h}$. In the JATOP study, permeation and

225 breakthrough emission amounts were not distinguished. Their total emission value

226 was considered. Conversely, in this study, the permeation values at all time 
periods, which were calculated using the temperature dependent equation (S1),

228 were taken into account, and treated separately.

229 - In the JATOP study, the parking frequency was assumed to be constant i.e.,

230 independent of the prefectural property. Conversely, in this study, the parking

231 frequency for each city was considered to be different as listed in Table S4.

232 - In this study, canister adsorption capacity deterioration was considered, and all the

233 adsorption capacities of the canisters were assumed to be half the adsorption

$234 \quad$ capacity listed in Table S3.

235 - In the JATOP study, the daily minimum and maximum environmental temperatures

236 needed to calculate breakthrough emissions were measured. However, in this

237 study, hourly environmental temperatures determined using WRF, which has a

238 high time resolution, were used to calculate the amounts of both permeation and

239 breakthrough evaporative emissions.

240 The comparative evaluation of the evaporative emission amounts obtained in the

241 JATOP study and in this study is presented in Table S8. For the JATOP study, the

242 evaluated term was 2010 , while that of this study was 2015 . These term differences

243 did not significantly affect the estimation results because it was presumed that over a

244 period of five years, the seasonal trend for environmental temperatures and vehicle 
number did not changed significantly. From Table S8, it is evident that the number of prefectures considered in the previous study as well as this study were the same.

247 Additionally, the results of the total emission calculations obtained in this study for

248 Tokyo, Kanagawa, Chiba, Saitama were higher than those obtained in the previous

249 study. However, the reverse trend was observed for the results obtained from Gunma,

250 Tochigi, Ibaraki. In this study, differences in the parking frequency of the different

251 cities were considered, and the parking frequencies of the former four prefectures

252 (urban area) were found to be relatively higher than those of the other prefectures.

253 Thus, the differences between the emission trends observed in the previous study

254 and those observed in this study could be attributed to these differences in parking

255 frequency, which were assumed to be the same for all the prefectures in the previous

256 study. Based on existing literature, the Reddy's equation used in the previous study

257 overestimates evaporative emission amounts from fuel tank. For this reason,

equation (S2) was rather used as a more suitable approach to estimate fuel tank

259 evaporation. Additionally, in the previous study, the effect of canister deterioration,

260 which was included in this study, was not considered, and the canister adsorption

261 capacities were set to be half the capacities listed in Table S3. Even though in this

262 study, fuel tank evaporation overestimation was solved by replacing Reddy's 
equation with equation (S2), the consideration of canister deterioration resulted in

264 higher evaporative emission overestimations compared with the previous study.

265 However, these two factors finally canceled each other out, resulting in just a small

266 difference in the total evaporative emissions. The impact of considering the canister

267 purge effect could not be evaluated from the results presented in Table S8. This is

268 because this effect is associated with that of canister deterioration, and could not be

269 isolated such that they could each be evaluated separately.

270 Despite the upgrade in the permeation and breakthrough evaporation calculation

271 method, an increase in the number of parameters compared with the previous study

272 brought about several uncertainties as described below.

273 - The averaged experimental results of canister purge flow rate was used in the

274 calculation process of equation (S3). The number of the experiments performed

275 was limited, and this could bring about calculation uncertainty, which could be

276 solved by making further experimental measurements of air purge flow rate, so as

277 to reduce parameter variability.

278 - WRF results were used to estimate hourly environmental temperatures, and the

279 variability of the calculation results could bring about uncertainty with respect to

280 the amount of evaporation; thus, careful WRF parameter settings were needed. 
- The canister deterioration factor could not be constant at 0.5 for all vehicle types in the real environment. The uncertainty of this factor could be mitigated by collecting more experimental data.

284 Given that it is difficult to completely eliminate these different uncertainties, the use of 285 this proposed model should take these setbacks into consideration.

286 A previous study ${ }^{7}$ suggested that the total evaporative emissions from both 287 permeation and breakthrough in China were $138990 \mathrm{t} / \mathrm{y}$, slightly higher than that in the Kanto region. Strategies for reducing VOC emissions should therefore be 289 implemented. The new method of evaluating detailed inventory proposed in this study can be used in other countries, especially in highly polluted regions, to manage 291 atmospheric pollution.

Table S8: Comparison of the calculated yearly evaporative emissions (t/y) of the

294 previous study with those of the present study in Kanto region of Japan.

\begin{tabular}{lccccccc}
\hline Emission type/Prefectures & Tokyo & Kanagawa & Chiba & Saitama & Gunma & Tochigi & Ibaraki \\
\hline Permeation (JATOP) & - & - & - & - & - & - & - \\
Breakthrough (JATOP) & - & - & - & - & - & - & - \\
Total (JATOP) & 730 & 630 & 520 & 710 & 290 & 260 & 360 \\
\hline Permeation (This study) & 348 & 296 & 244 & 307 & 81 & 75 & 118 \\
Breakthrough (This study) & 685 & 463 & 394 & 542 & 132 & 96 & 180 \\
Total (This study) & 1,033 & 759 & 638 & 849 & 213 & 171 & 298 \\
\hline
\end{tabular}


297 5. Technological report of JATOP. Japan Auto Oil Program. 2012.

298 6. Reddy, S. R. Prediction of fuel vapor generation from a vehicle fuel tank as a

299 function of fuel RVP and temperature. SAE Technical Paper Series. 1989, 892089.

$300 \quad$ https://doi.org/10.4271/892089.

301 7. Liu, H.; Man, H.; Tschantz, M.; Wu, Y.; He, K.; Hao, J. VOC from Vehicular

302 Evaporation Emissions: Status and Control Strategy. Environmental Science \&

303 Technology. 2015, 49(24), 14424-14431. https://doi.org/10.1021/acs.est.5b04064. 
305

306

307

308

309

310

311

312

313

\section{Section S10 Reproducibility of ambient temperature calculated using}

\section{WRF}

In this study, a new method of evaluating evaporative emissions from parked gasoline vehicles was introduced, and diurnal temperature data were evaluated using WRF. Therefore, the reproducibility of the calculated temperatures compared with that of observed temperatures should be confirmed. Figures S9-S12 show the comparison between observed and calculated temperatures in the seven capital cities where the temperatures were used to analyze the CMAQ calculation results in the main article. The analysis period lasted from July 10 to August 15, 2015, which corresponded to the CMAQ calculation period. Figures S9-S12 show that the WRF-calculated temperatures were highly reproducible compared to the observed data. Nonetheless, in some cases, the WRF calculation results over- or underestimated the observed temperature. In the previous method of evaluating diurnal evaporation from parked vehicles, daily minimum and maximum temperatures according to the linear interpolation method were used, and the detailed time resolution of the temperatures was not considered. Thus, we conclude that using WRF-calculated temperatures could be effective for obtaining temperatures with 
322 higher time resolution, in spite of the over- or underestimations of the observed

323 value.
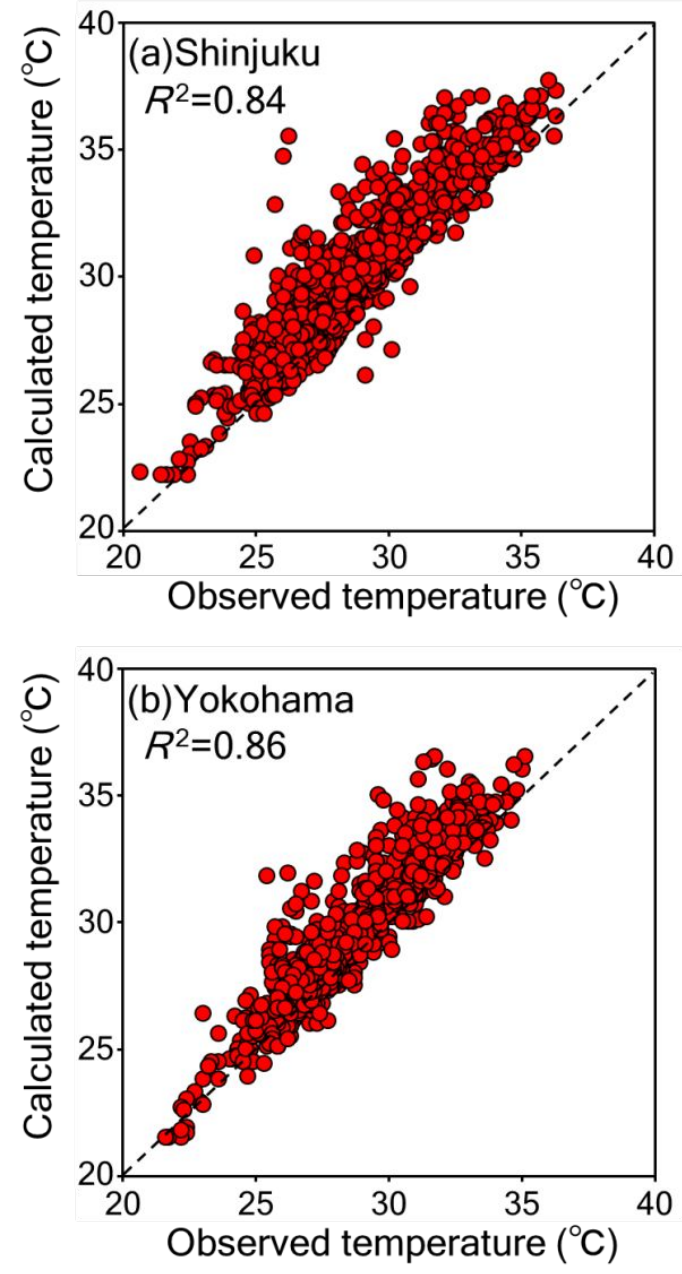

325 Figure S9: Comparison of ambient temperatures between observed and weather

326 research and forecasting model-calculated temperatures in (a) Shinjuku and (b)

Yokohama from July 10 to August 15, 2015. 

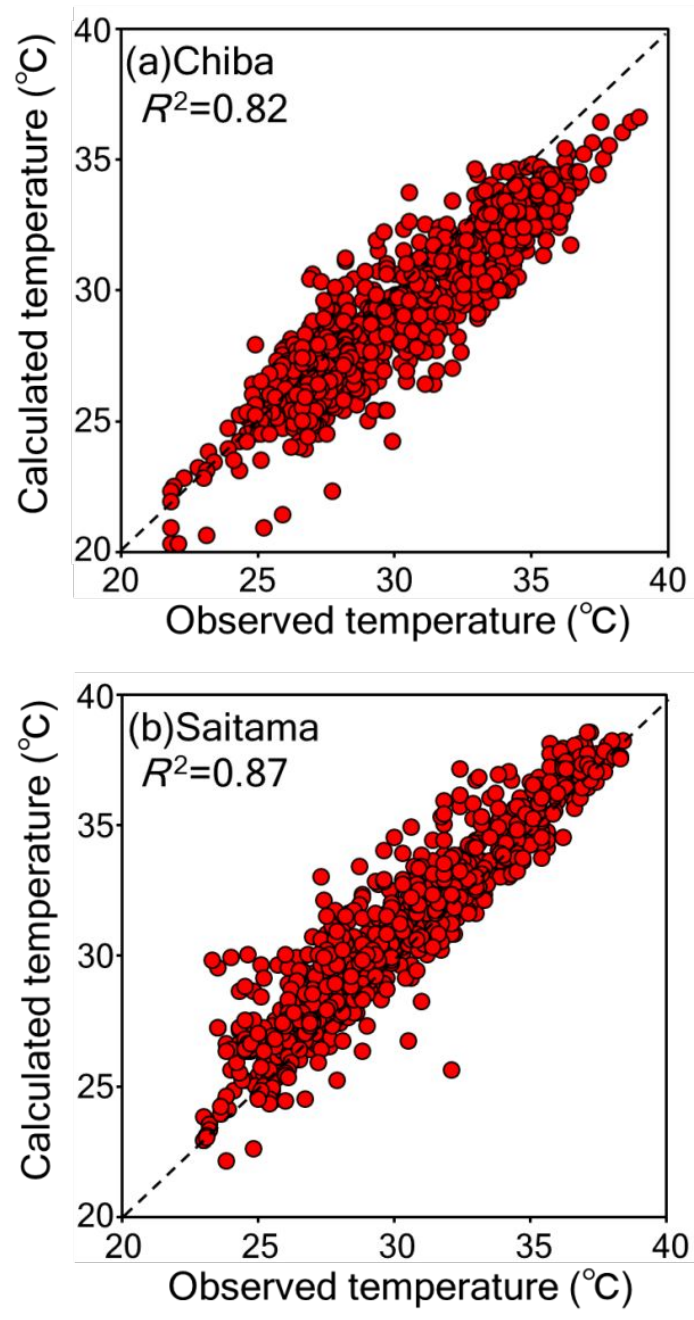

Figure S10: Comparison of ambient temperatures between observed and weather

331 research and forecasting model-calculated temperatures in (a) Chiba and (b)

332 Saitama from July 10 to August 15, 2015. 

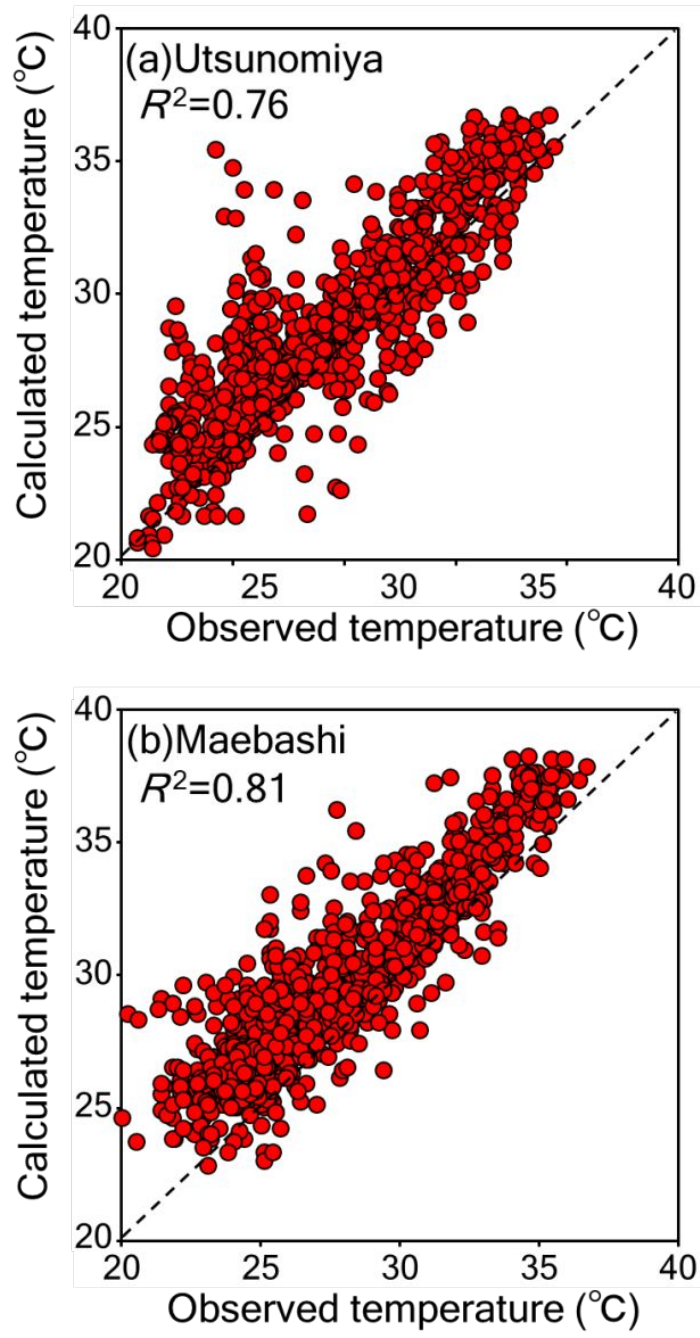

Figure S11: Comparison of ambient temperatures between observed and weather

335 research and forecasting model-calculated temperatures in (a) Utsunomiya and (b)

336 Maebashi from July 10 to August 15, 2015. 


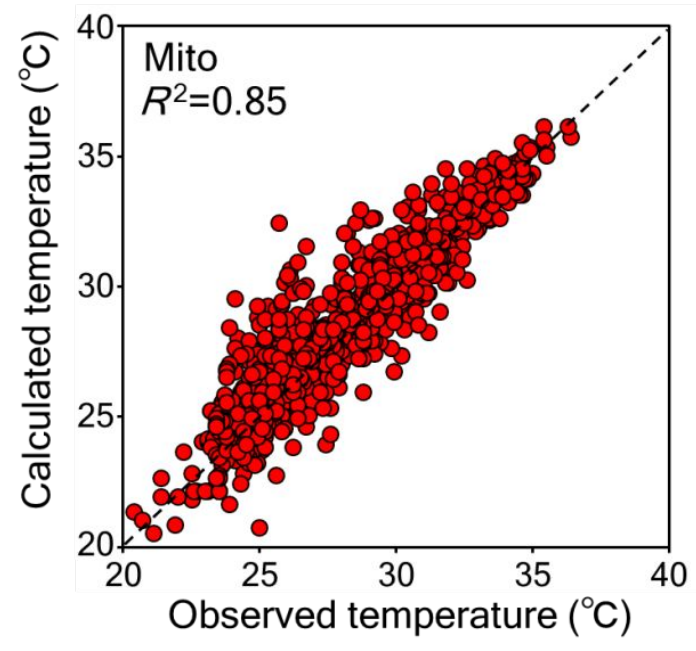

340 Figure S12: Comparison of ambient temperatures between observed and weather

341 research and forecasting model-calculated temperatures in Mito from July 10 to

342 August 15, 2015. 
344 Text S11 Model validation for tropospheric ozone and $P M_{2.5}$

345 concentration in seven prefectures in Japan.

346 A comparison between the tropospheric ozone and $\mathrm{PM}_{2.5}$ concentration found in the

347 CMAQ calculation results and the observed data ${ }^{8}$ is shown in Figures S13 and S14.

348 The places analyzed in this study were the capital cities in the 7 prefectures:

349 Shinjuku (Tokyo), Yokohama (Kanagawa), Chiba (Chiba), Saitama (Saitama),

350 Utsunomiya (Tochigi), Maebashi (Gunma), and Mito (Ibaraki). In terms of the $\mathrm{PM}_{2.5}$

351 concentration in Saitama and Mito, the monitoring systems were different for the

352 other four cities and were less accurate because of the machine's characteristics ${ }^{9}$, so

353 the observed data from Saitama and Mito are not shown in Figure S14. From Figure

$354 \mathrm{~S} 13$, the calculation results for ozone concentration reproduced the observed data

355 well in terms of both time profile and absolute value, with correlation factors ranging

356 from 0.65 to 0.83 . As shown in Figure $\mathrm{S} 14$, the calculation results for $\mathrm{PM}_{2.5}$, aside

357 from Saitama and Mito, also replicated the observed results well. Therefore, while we

358 could not confirm the validity of the $\mathrm{PM}_{2.5}$ concentration in Saitama and Mito, we

359 concluded that $\mathrm{PM}_{2.5}$ concentration calculated using the CMAQ could be used in the

360 sensitivity analysis in this study. 

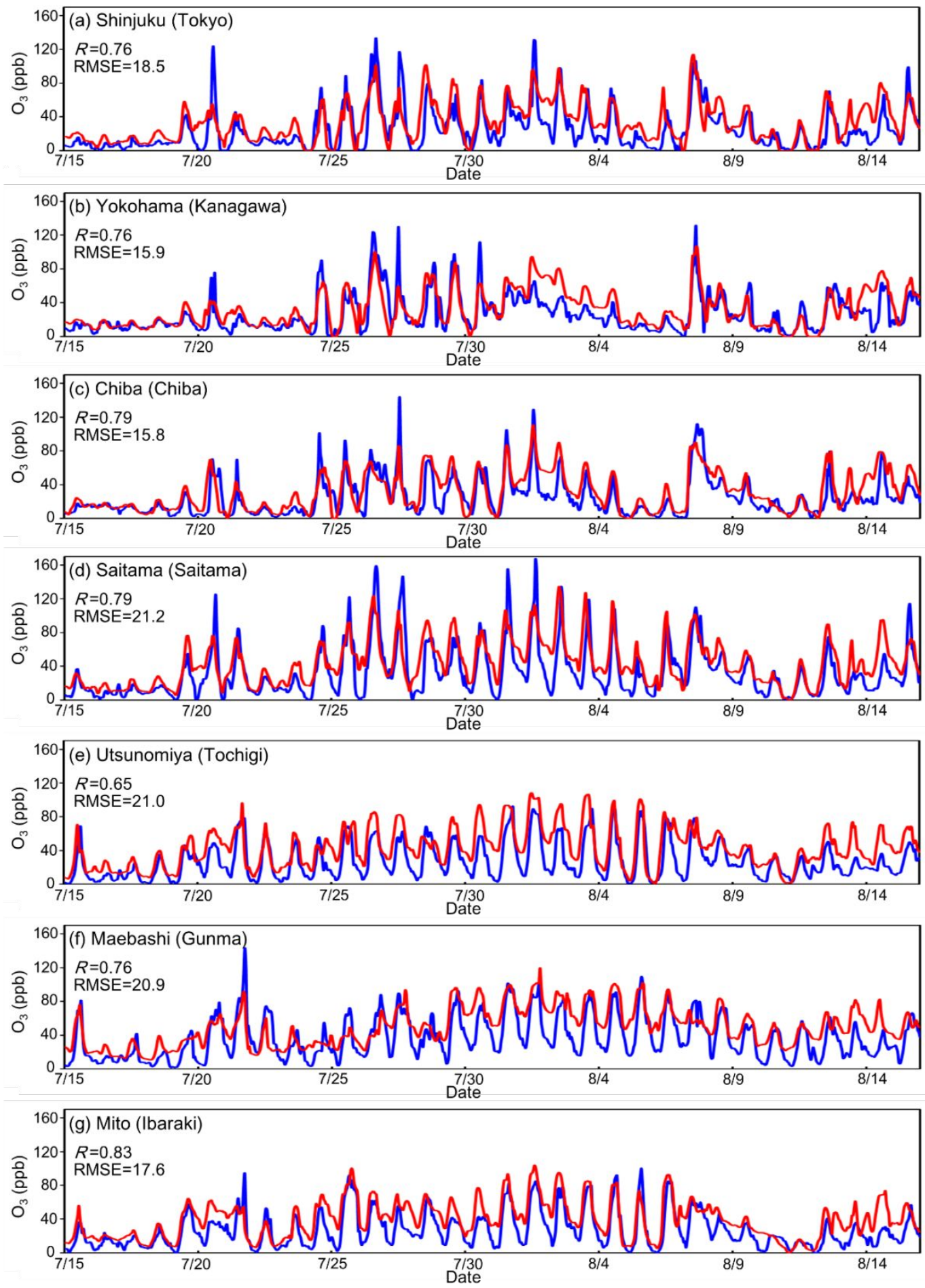

362 Figure S13: Comparison between the CMAQ calculation results and observational data for tropospheric ozone concentration. 

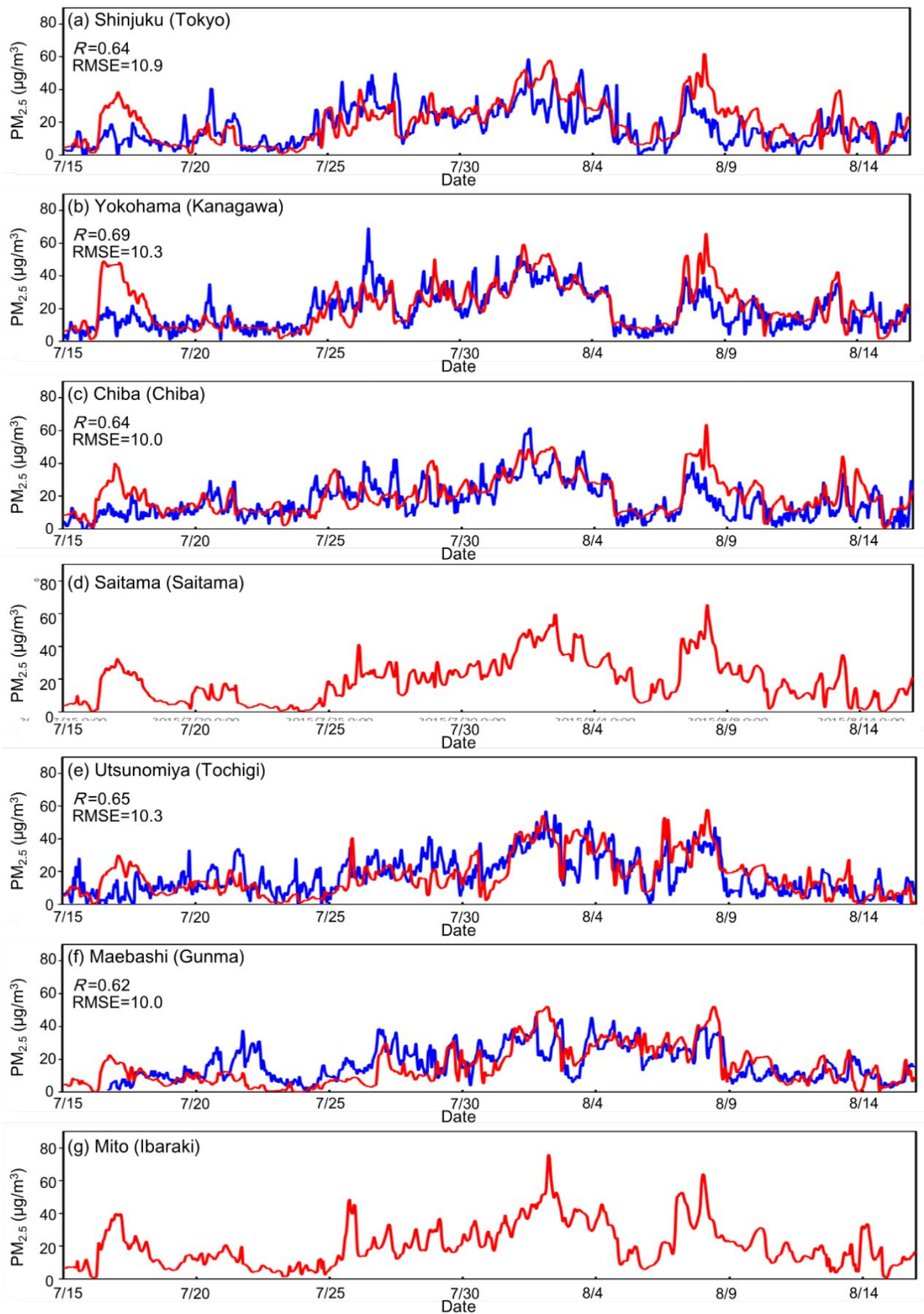
366 Figure S14: Comparison between the CMAQ calculation results and observational

367 data for $\mathrm{PM}_{2.5}$ concentration.

368 Text S11 Reference

369 8. National Institute for Environmental Study.

370 https://www.nies.go.jp/igreen/tm_down.html.

371 9. Hasegawa, Shuichi.; Yamagami, Makiko.; Suzuki, Yoshihiro.; Kumagai, Kimiyo.;

372 Nishimura, Rie. Verification of Measured Values by $\mathrm{PM}_{2.5}$ Automatic Measuring

373 Instruments Using the Standard Method. JOURNAL OF ENVIRONMENTAL

374 LABORATORIES ASSOCIATION. 2018, 43, 1. 
Text S12 Ozone concentration and wind-vector map.
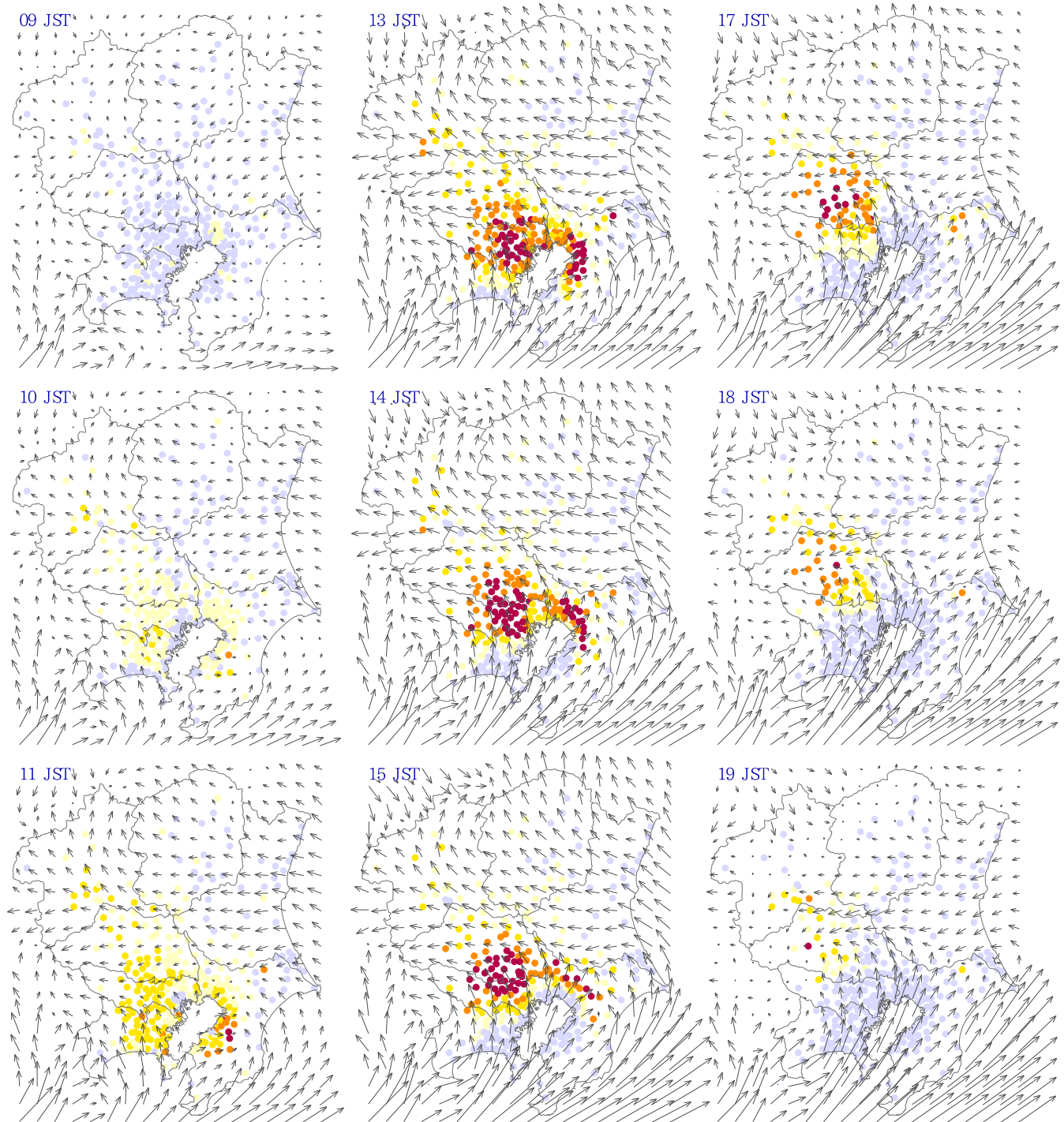

19 JST
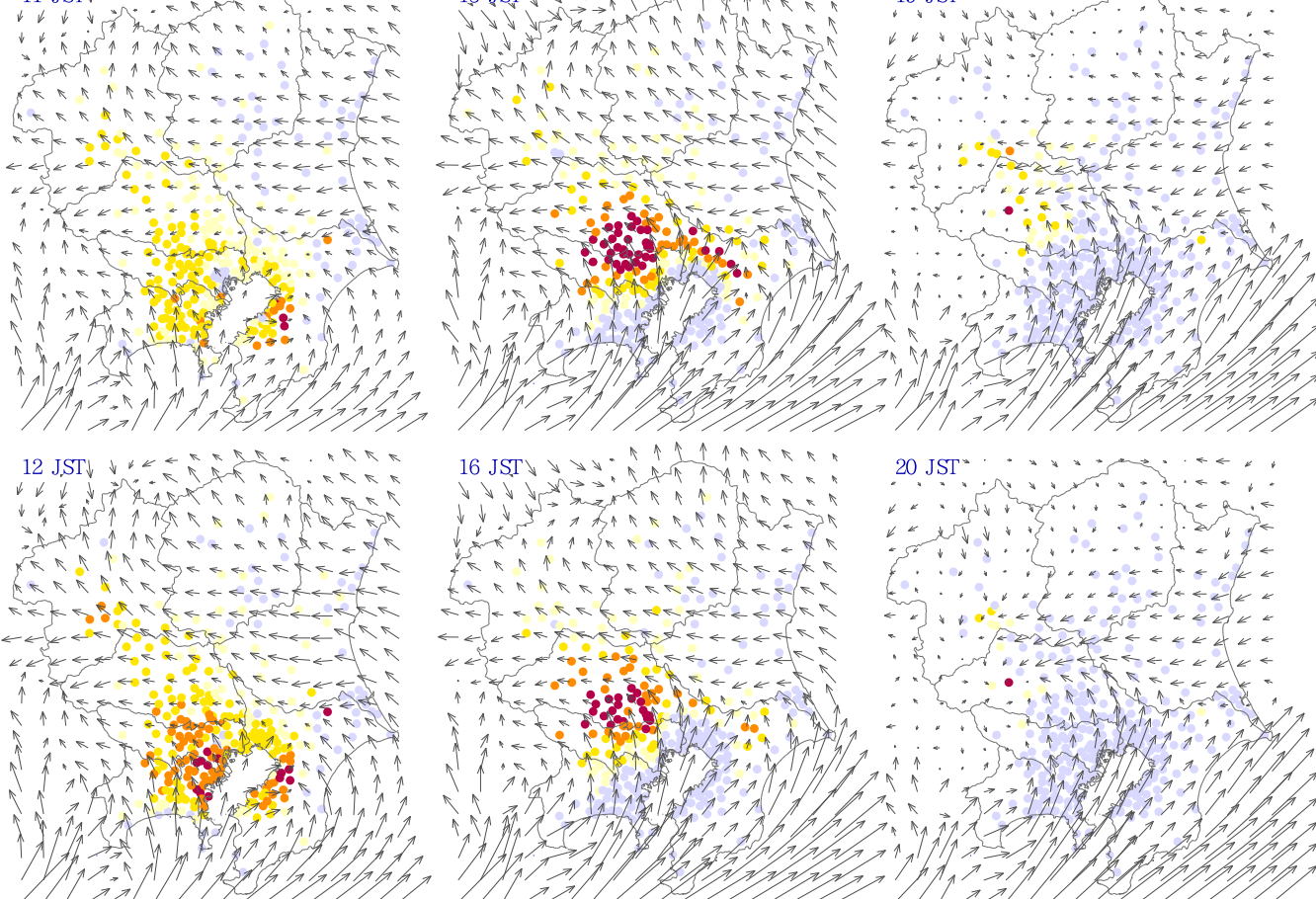

$20 \mathrm{JST}^{-}$

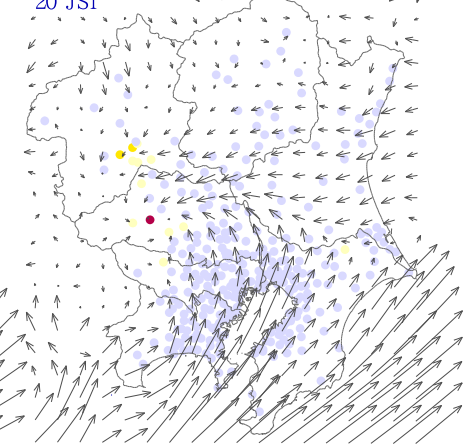

120ppb - $\underset{5 \mathrm{~m} / \mathrm{s}}{\longrightarrow}$ 
Figure S15: Hourly observed ozone concentration and wind-vector analysis for July 

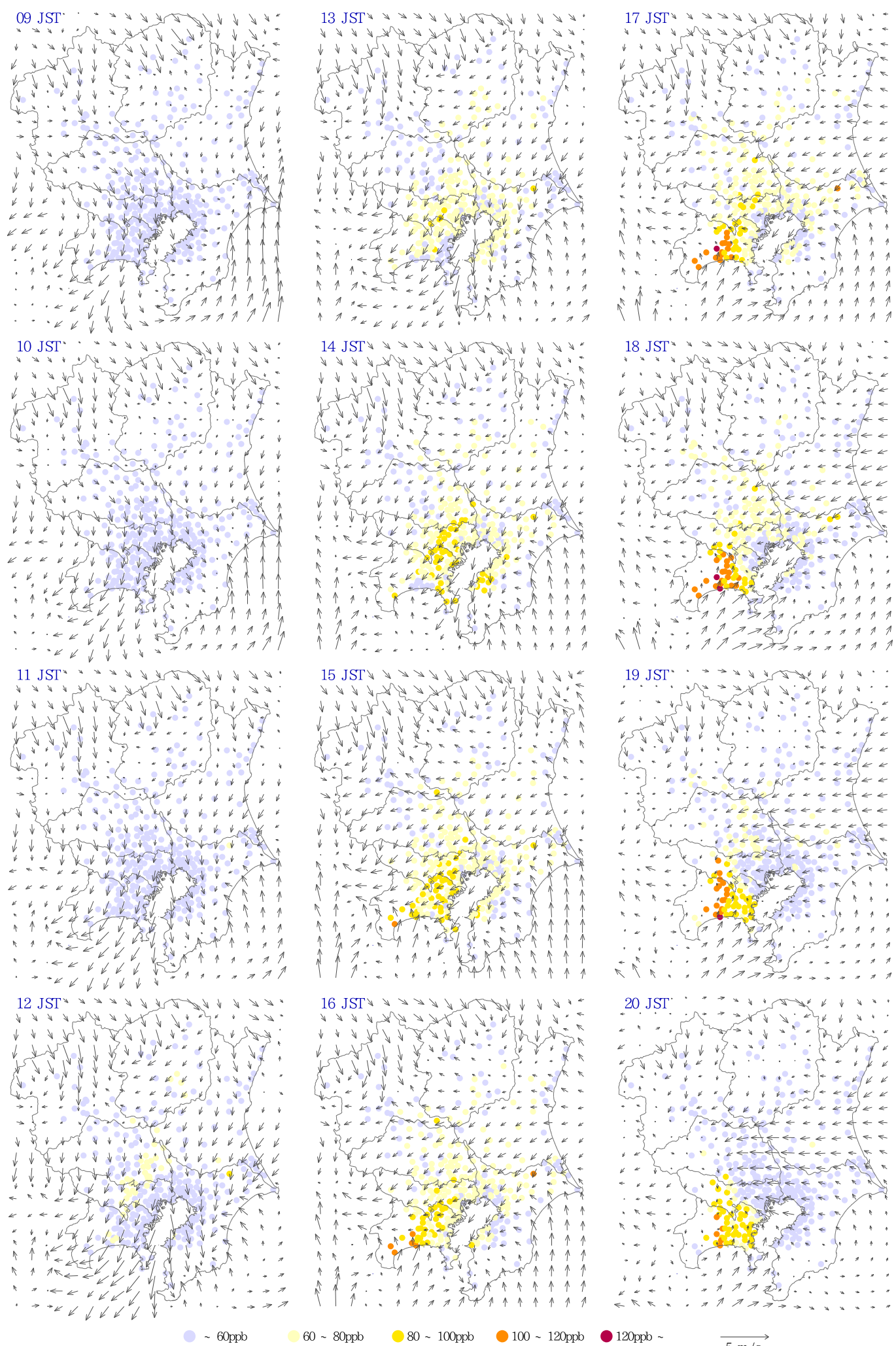
Figure S16: Hourly observed ozone concentration and wind-vector analysis for July

\section{Text S13 Time profile of calculated evaporative emissions}

384 The time profiles of the calculated evaporative emissions in the seven cities of Kanto

385 region are depicted in Figure S17. These profiles show that while the evaporation

386 from permeation had a similar trend during the analysis period, breakthrough

387 emissions had typical daily time trends, with high emissions. Breakthrough emissions

388 are a function of canister purge rate and parking time, and the time trend was

389 therefore clearer than that of permeation emissions. 

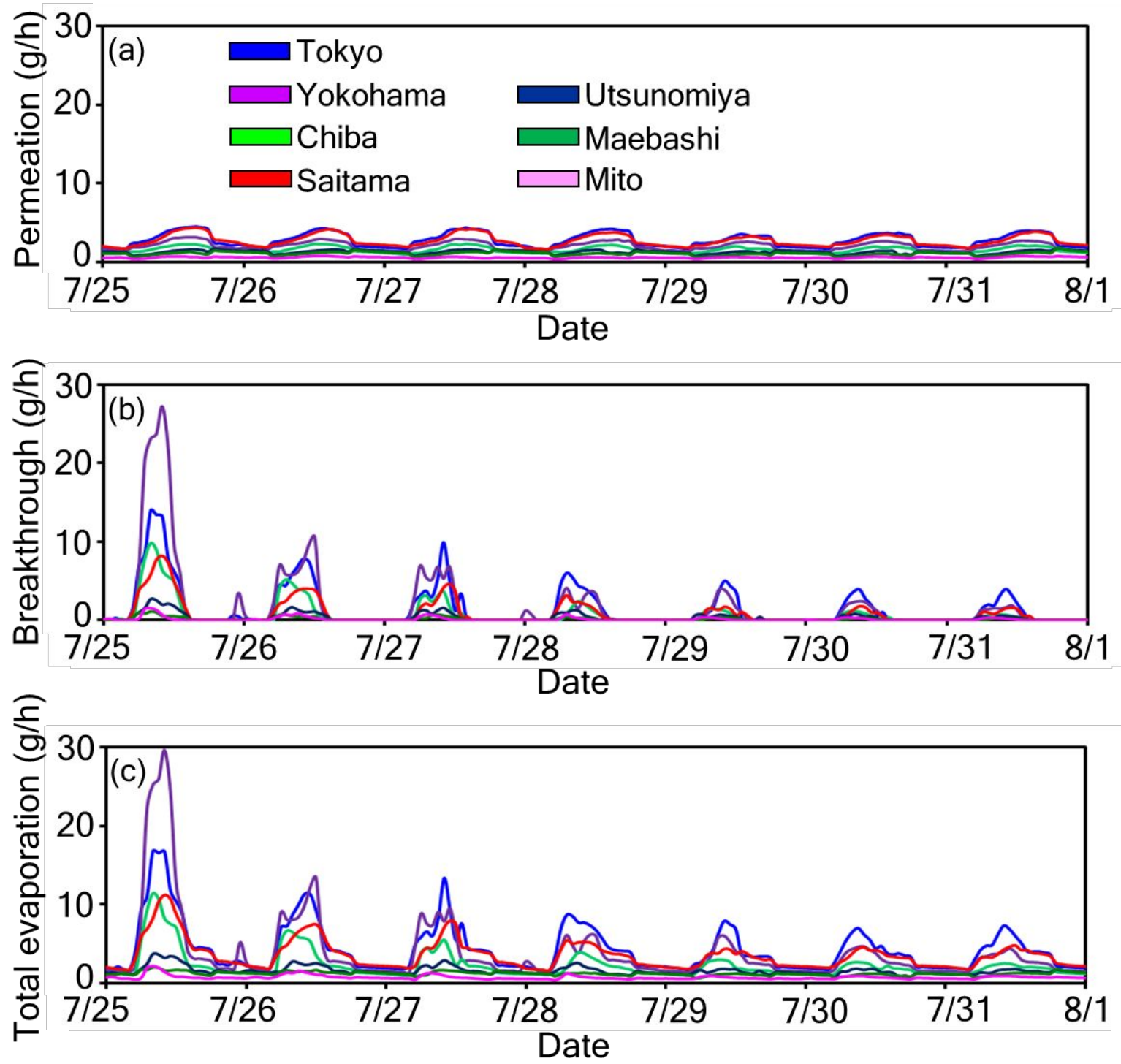

391 Figure S17: Time profile of summertime evaporative emissions in seven prefectural

392 cities for (a) permeation, (b) breakthrough, and (c) total evaporation of permeation 393 and breakthrough. 

set to zero). The HSL inventory employed in the evaluation was not created in this study. Rather, it was obtained from the JATOP study (targeted period of the inventory, 2010). The VOC composition of HSL in SAPRC07 was set to be the same as that of the permeation emission (Figure S5). Figure S18(a) shows that with respect to ozone formation, HSL resulted in approximately equal amounts of ozone for breakthrough 402 emission (Figure 2(b) in main article), and a lesser amount for permeation emission 403 (Figure 2(a) in main article). Additionally, Figure S18 (b) shows that the effect of HSL 404 on SOA formation was higher than that for breakthrough emission (Figure 2(e) in the main article), and a lesser amount for permeation emission (Figure 2(d) in the main article). Thus, it was concluded that permeation emission is the most important factor in the formation of tropospheric ozone and SOA. 
Shinjuku OYokohama Ochiba OSaitama Outsunomiya OMaebashi OMito

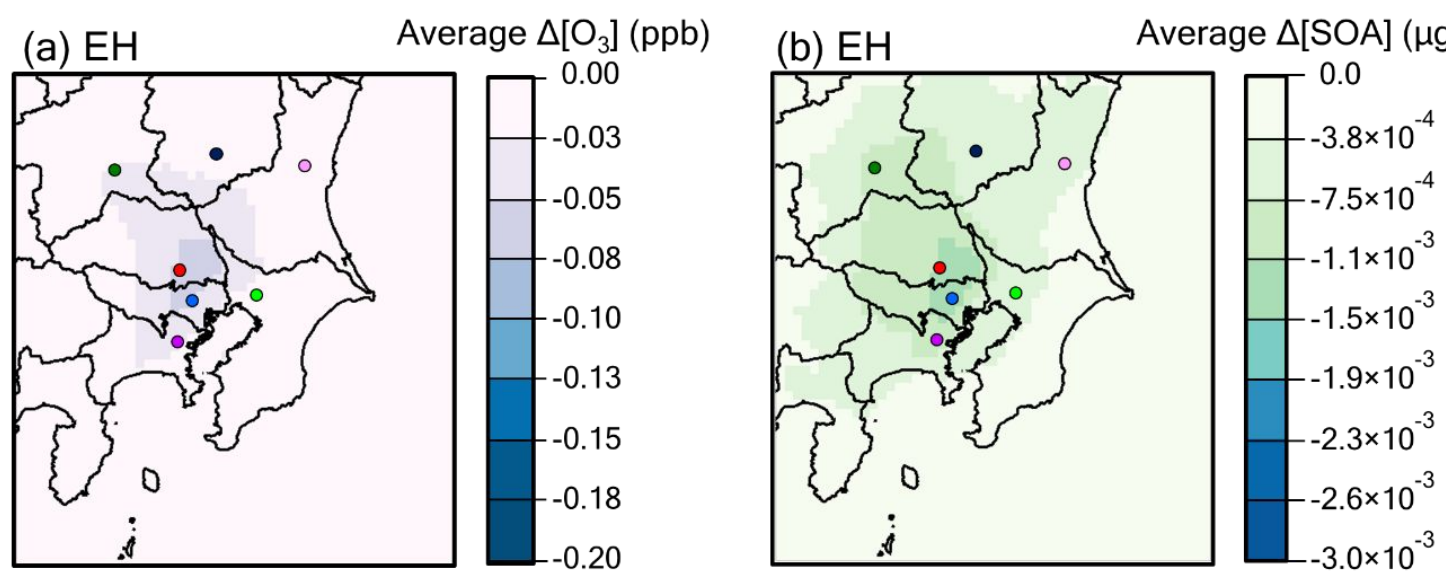

Figure S18: The results of the sensitivity analysis of the reduction in evaporative

411 emissions for (a) Ozone with hot-soak loss, and (b) SOA without hot-soak loss. 